\title{
ELECTRODE BEHAVIOUR OF NICKEL IN HCl-DIMETHYLSULPHOXIDE SOLUTIONS-I. THE CATHODIC EVOLUTION OF HYDROGEN
}

\author{
A. Delgado, D. Posadas and A. J. Arvía \\ Instituto de Investigaciones Fisicoquimicas Teóricas y Aplicadas, División Electroquimica, Facultad \\ de Ciencias Exactas, Universidad Nacional de La Plata, La Plata, Argentina
}

(Revised version 15 December 1972)

\begin{abstract}
The electrochemical reduction of the solvated hydrogen ion dissolved in DMSO as $\mathrm{HCl}$ was investigated from 25 to $45^{\circ} \mathrm{C}$, at different concentrations and ionic strength. Stationary and nonstationary techniques were employed to obtain the kinetic parameters. The results were interpreted with a rcaction scheme involving an initial clectron transfer as $r d s$, probably followed by an electrochemical desorption step.
\end{abstract}

\section{INTRODUCTION}

The electrochemical reduction of the solvated proton in DMSO was already studied on various metals, such as platinum, iron and mercury[1-5], attempting to evidence any possible influence of the solvent in the course of the reactions.

For metals undergoing corrosion and passivation, such as iron[6,7], in solutions of $\mathrm{HCl}$ in DMSO the knowledge of the kinetics and mechanism of the solvated proton discharge is required for a complete interpretation of the electrode behaviour.

Nickel corrodes and passivates in DMSO solutions containing $\mathrm{HCl}$. The present paper refers to the cathodic evolution of hydrogen on this metal, as part of its electrochemical behaviour in those solutions.

\section{EXPERIMENTAL}

The electrolysis cell was the same previously reported[3,6,7]. Nickel rotating disc electrodes of $2.8 \mathrm{~mm}$ dia concentrically embedded in a Teflon rod of $15 \mathrm{~mm}$ dia were used. Static electrodes formed by sectioning of the nickel-teflon rod cut at $45^{\circ}$ angle were also employed. The purity of the metal was 99.95 (impurities in ppm: $0.2 \mathrm{C} ; 0.005 \mathrm{Fe}$; $0.005 \mathrm{Mn} ; 0.005 \mathrm{Cu} ; 0.005 \mathrm{Cr} ; 0.005 \mathrm{~S} ; 0.005 \mathrm{Si}$; $0.003 \mathrm{Ti}$ and $0.003 \mathrm{Co}$ ). The electrode area was $6.15 \times 10^{-2} \mathrm{~cm}^{2}$ for the rotating disc and 8.79 $\times 10^{-2} \mathrm{~cm}^{2}$ for the static electrode.

An aqueous saturated calomel electrode properly shielded to avoid solution mixing, was used as reference electrode. The solvent (DMSO) was purified as reported elsewhere[3], the water content being about $400 \mathrm{ppm}$. Hydrogen chloride solutions were prepared as indicated[3,4]. Solutions were employed under a stream of purified hydrogen gas passing through. Hydrogen chloride concentration was changed from 0.001 to $0.125 \mathrm{M}$. Most of the experiments were done with sulutions containing $1 M$ potassium perchlorate (saturated with potassium chloride) as supporting electrolyte. Solutions containing I $M$ lithium perchlorate $(0 \cdot 1 \mathrm{M}$ chloride ion, obtained by adding either lithium chloride or hydrogen chloride) were employed. A $0.944 M$ hydrogen chloride solution without supporting electrolyte was also studied.

Current-potential curves were run both under galvanostatic and potentiostatic conditions with the disc electrode rotating at different speeds. Triangular potential sweep voltammetry was also employed. The galvanostatic cathodic overpotential build-up and its decay at current interruption were recorded. Experiments were run within the temperature range $25-45^{\circ} \mathrm{C}$.

\section{RESULTS}

\section{Current efficiency}

The efficiency for the hydrogen evolution, measured at different current densities from 850 to $1240 \mu \mathrm{A} / \mathrm{cm}^{2}$ was comprised between 93 and $99 \%$.

\section{Current-potential curves}

Both potentiostatic and potentiodynamic currentpotential curves were recorded from the initial rest potential toward cathodic potentials, either with the cathode at rest or under rotation. These curves depend principally on hydrogen chloride concentration and temperature (Figs. 1 and 2). The currentpotential curves display Tafel regions which are independent of the stirring conditions. At high cathodic potential and at low hydrogen chloride 


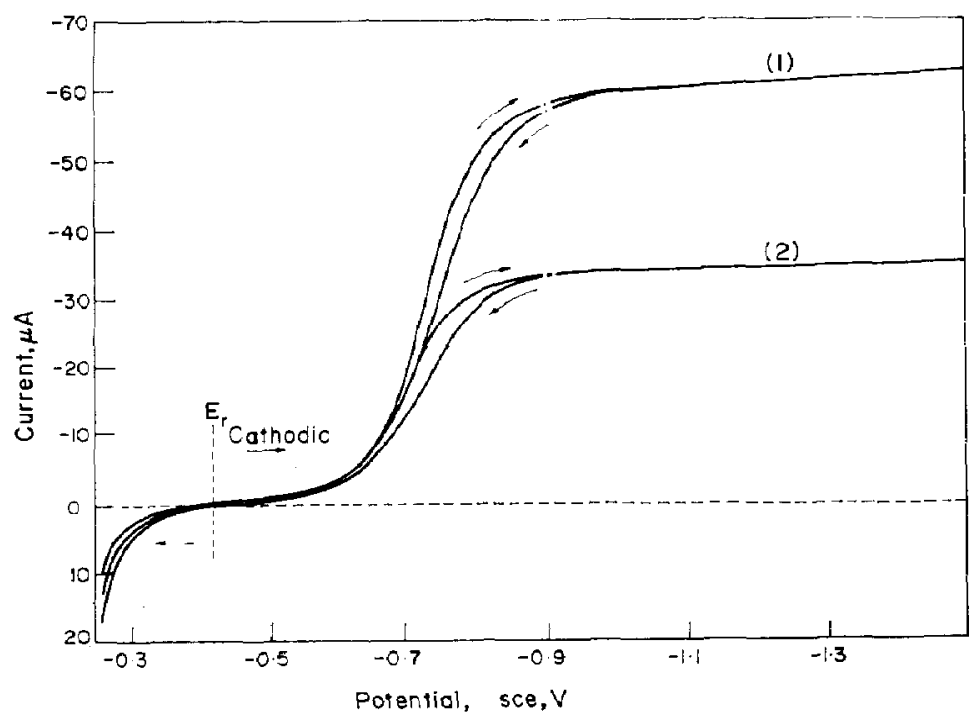

Fig. 1. Voltammograms obtained at $10 \mathrm{mV} / \mathrm{s}$ and $25^{\circ} \mathrm{C}$. Solution composition $0.010 \mathrm{M} \mathrm{HCl}+1 \mathrm{M}$ $\mathrm{LiClO}_{4}\left(0 \cdot 100 \mathrm{M} \mathrm{Cl}^{-}\right)$. Rotation speeds: $95 \cdot 7 / \mathrm{s}(1)$ and 32.7/s (2).

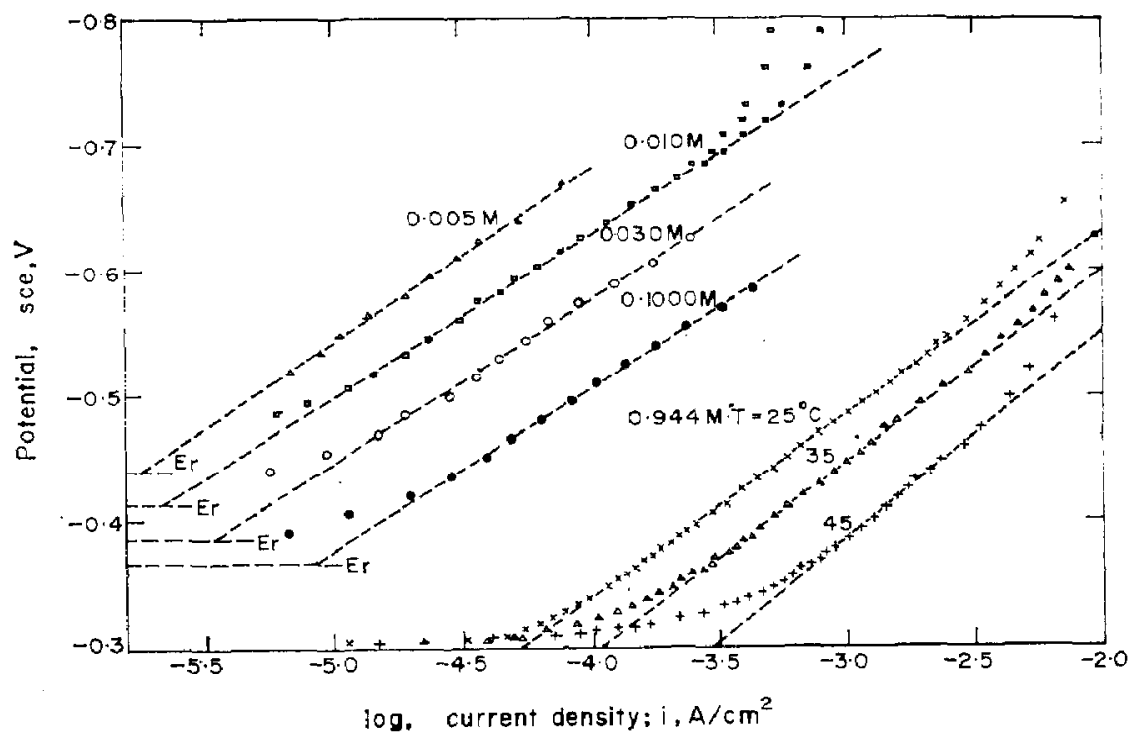

Fig. 2. Potential-log (apparent current density) plots at different concentrations and temperatures; $\Delta, \square, O, \quad$, data from voltammograms obtained at $10 \mathrm{mV} / \mathrm{s}, 25^{\circ} \mathrm{C}$ and $32.7 / \mathrm{s}$ (rotation speed). Solution composition X M HCl $+1 \mathrm{M} \mathrm{LiClO}_{4}\left(0 \cdot 100 \mathrm{M} \mathrm{Cl}^{-}\right)$, the X's are indicated in the figure. $\times, \Delta,+$, data obtained potentiostatically at $95.7 / \mathrm{s}$.

concentrations, a convective-diffusion controlled region is observed (Fig. 2, $0.010 \mathrm{M} \mathrm{HCl}$ solution). The voltammograms run at potential sweep rates larger than $30 \mathrm{mV} / \mathrm{s}$ exhibit a cathodic current peak related to the diffusion of the solvated proton. No anodic current peak was detected during the returning half-cycle from cathodic to anodic potentials.

The current-potential curves obtained by changing the potential from cathodic to anodic direction, starting at a potential where the limiting current plateau is observed, exhibit hysteresis. Then, an apparent potential arrest occurred at potentials more cathodic than the rest potential, the latter being recovered rather slowly.

The stationary cathodic Tafel slope, at $25^{\circ} \mathrm{C}$, is between 116 and $124 \mathrm{mV}$ per decade for the rotating nickel electrode and $\mathrm{KCl}($ sat $)+1 \mathrm{MKClO}_{4}+\mathrm{XM}$ $\mathrm{HCl}$ solution $(0.001 \leq \mathrm{X} \leq 0.125)$; for solution without supporting electrolyte its value is $146 \mathrm{mV}$ per 
decade. Experiments run with the electrode at rest exhibit a Tafel slope comprised between 133 and 178 $\mathrm{mV}$ per decade within the $\mathrm{X}$ values just reported. The cathodic Tafel slope increases with temperature, as expected.

Data derived from $E / I$ curves obtained at $10 \mathrm{mV} / \mathrm{s}$ are assembled in Table $1 . b_{T}$ is the cathodic Tafel

Table 1. Kinetic parameters derived from cathodic $E / I$ voltammograms at $10 \mathrm{mV} / \mathrm{s}$. Solution composition:

$1 M \mathrm{LiClO}_{4}+\mathrm{X}^{\prime} M \mathrm{LiCl}+\mathrm{X} M \mathrm{HCl} .\left(\mathrm{X}+\mathrm{X}^{\prime}=0 \cdot 1\right)$

\begin{tabular}{ccccc}
\hline$T$ & $\mathrm{X}^{\prime}$ & $\mathrm{X}$ & $b_{T}$ & $\begin{array}{c}\left(i_{0}\right)_{E_{r}} \\
\mathrm{C}\end{array}$ \\
\hline$M$ & $M$ & $\mathrm{mV}$ & $\mu \mathrm{A} / \mathrm{cm}^{2}$ \\
\hline 25 & 0.095 & 0.005 & $140 \pm 20$ & $1 \cdot 70$ \\
& 0.090 & 0.010 & 134 & $2 \cdot 09$ \\
& 0.070 & 0.030 & 133 & 3.47 \\
25 & - & 0.100 & 127 & $8 \cdot 70$ \\
35 & - & 0.100 & 142 & - \\
45 & - & 0.100 & 157 & - \\
\hline
\end{tabular}

slope and $\left(i_{0}\right)_{E_{T}}$ is the apparent current density extrapolated at the rest potential, $E_{r}$.

The cathodic limiting current increases linearly both with the square root of the rotation speed of the working electrode and with the hydrogen chloride concentration (Fig. 3). The experimental diffusion coefficient, as calculated from the limiting current obtained with the nickel rotating disc electrode and Levich equation[8], is $(1.5 \pm 0.1) \times 10^{-6} \mathrm{~cm}^{2} / \mathrm{s}$, at $25^{\circ} \mathrm{C}$, for the solution composition $\mathrm{KCl}$ (sat) $+1 \mathrm{M}$ $\mathrm{KClO}_{4}+\mathrm{X} \mathrm{M} \mathrm{KCl}(0.025 \leq \mathrm{X} \leq 0.125)$. That figure agrees with earlier published results[1].

Stationary current-potential curves were also run starting from the initial rest potential toward anodic potentials. The reaction occurring there at low anodic overvoltage is the dissolution of the metal, which will be reported in detail in a forthcoming publication [9], but it is worthwhile to mention it here, although briefly, because of the definition of the corrosion potential of nickel in these solutions.

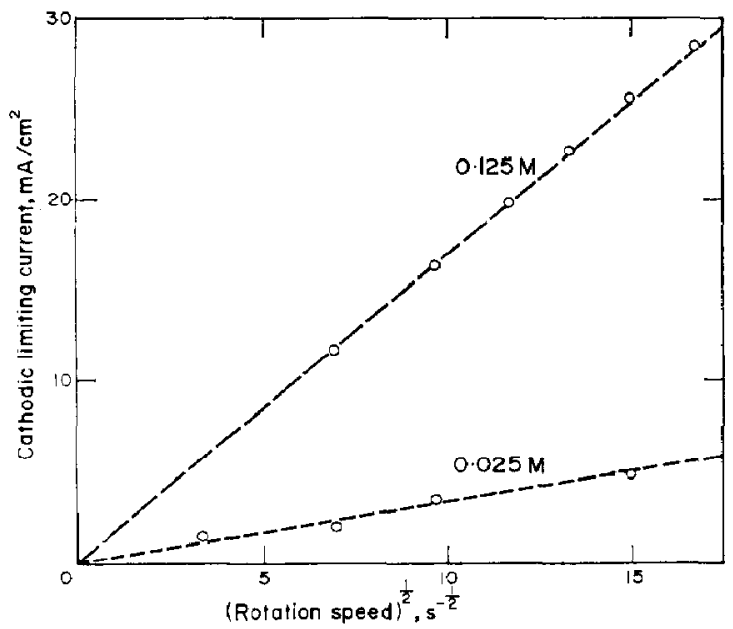

Fig. 3. Dependence of the cathodic limiting current density on the square root of the rotation speed; $25^{\circ} \mathrm{C}$; solution composition: $1 \mathrm{M} \mathrm{KClO}_{4}+\mathrm{KCl}$ (sat) $+\mathrm{X} M$ $\mathrm{KCl} . \mathrm{X}$ is indicated in the figure.

\section{The rest potential}

The rest potential of the working electrode, $E_{r}$, at constant ionic activity, depends on the logarithm of the hydrogen ion concentration, at $25^{\circ} \mathrm{C}$, as given by the following expression:

$$
E_{r}(\text { sce })(\text { in } V)=(-0.298 \pm 0.020)-0.0592 \log \mathrm{C}_{\mathrm{H}^{+}}
$$

as shown in Fig. 4. The slope $\left(\Delta E_{\mathrm{r}} / \Delta \log \mathrm{C}_{\mathrm{H}^{+}}\right)$ approaches the value $2 \cdot 3(R T / F)$.

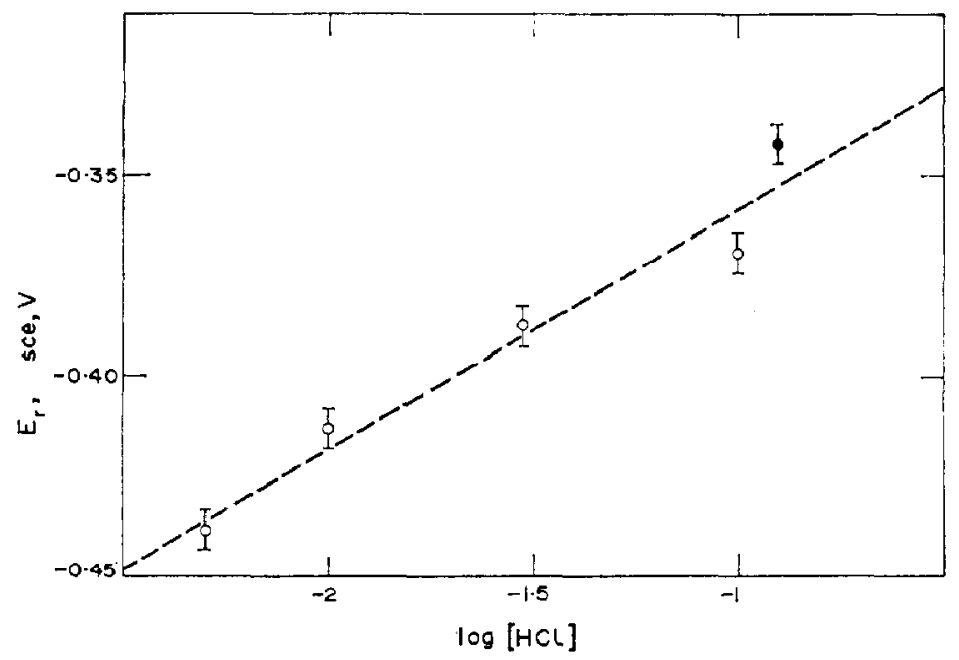

Fig. 4. Dependence of the rest potential on the concentration of $\mathrm{HCl}$ at $25^{\circ} \mathrm{C}$, in the presence of $1 M \mathrm{KClO}_{4}+\mathrm{KCl}($ sat $)(\mathrm{O})$ and $1 M \mathrm{LiClO}_{4}(\mathrm{O})$. 


\section{Electrode differeniial capacitance}

The cathodic overvoltage decay data at current interruption show reasonable linear dependences between electrode potential and logarithm of time, within the same potential range where the Tafel line was found for the stationary $E / I$ curves. The experimental electrode differential capacitances corresponding to the potential of current interruption are within 5 and $12 \mu F / \mathrm{cm}^{2}$, and exhibit no dependence on electrode potential, at least within the Tafel region.

From the galvanostatic potential build-up, the apparent electrode differential capacitance at the initial potential was, at $25^{\circ} \mathrm{C}, 12 \pm 4 \mu \mathrm{F} / \mathrm{cm}^{2}$. The coincidence with values reported from decay curves at different potentials is reasonable and probably suggests that no significant modification in the electrochemical interface occurs during the reaction.

\section{Dependence of the Tafel line region on hydrogen ion concentration}

For evaluating the reaction orders only those solutions containing an excess of supporting electrolyte were considered.

At constant temperature, chloride ion concentration and electrode potential, the cathodic current increases with the hydrogen chloride concentration (Fig. 2). At constant cathodic potential, the reaction order, $\left(\partial \log i / \partial \log \mathrm{C}_{\mathbf{H}}\right)_{E}$ is practically equal to 1 (Fig. 5). At constant overvoltage, $E-E_{r}$, the reaction order, $\left(\partial \log i^{\prime} \partial \log C_{H_{+}}\right)_{E-E_{r}}$ is close to $1 / 2$ (Fig. 6).

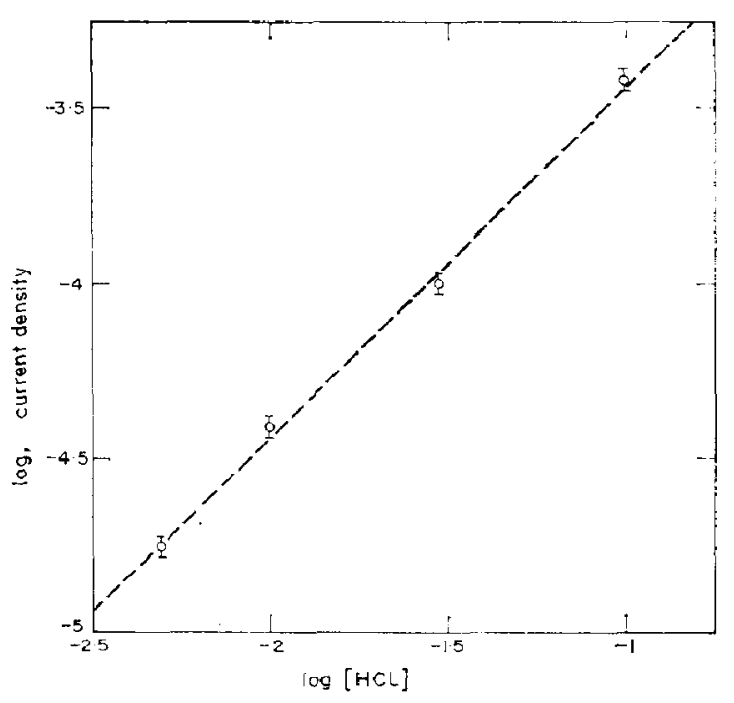

Fig. 5. Plot of log (apparent current density) vs log (hydrogen chloride concentration) with data from Fig. 2 at $E$ (vs sce $)=-0.580 \mathrm{~V}$, at constant chloride ion concentration and $25^{\circ} \mathrm{C}$.

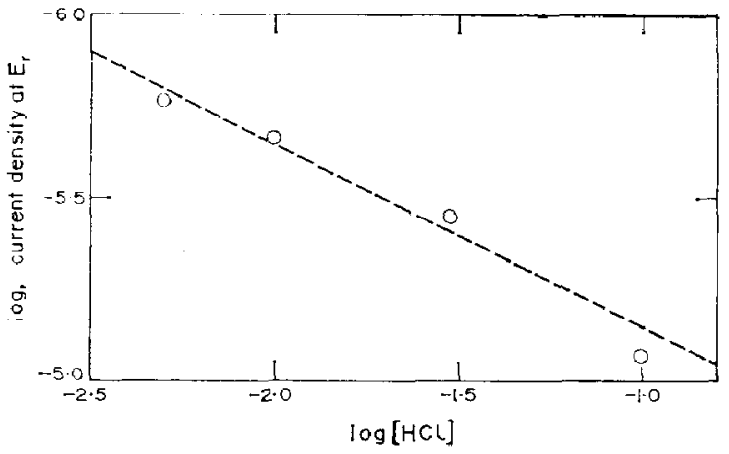

Fig. 6. Plot of $\log$ (apparent current density at $E_{r}$ ) vs $\log$ (hydrogen chloride concentration) with data from Fig. 2, at constant chloride ion concentration and $25^{\circ} \mathrm{C}$.

At constant temperature, chloride ion concentration and current, the overvoltage increases with the hydrogen ion concentration, as shown in Fig. 7 . The slope drawn corresponds to $\left[\partial\left(E-E_{\mathrm{r}}\right) / \partial \log \mathrm{C}_{\mathbf{H}^{+}}\right]_{l}=$ $60 \mathrm{mV} /$ decade.

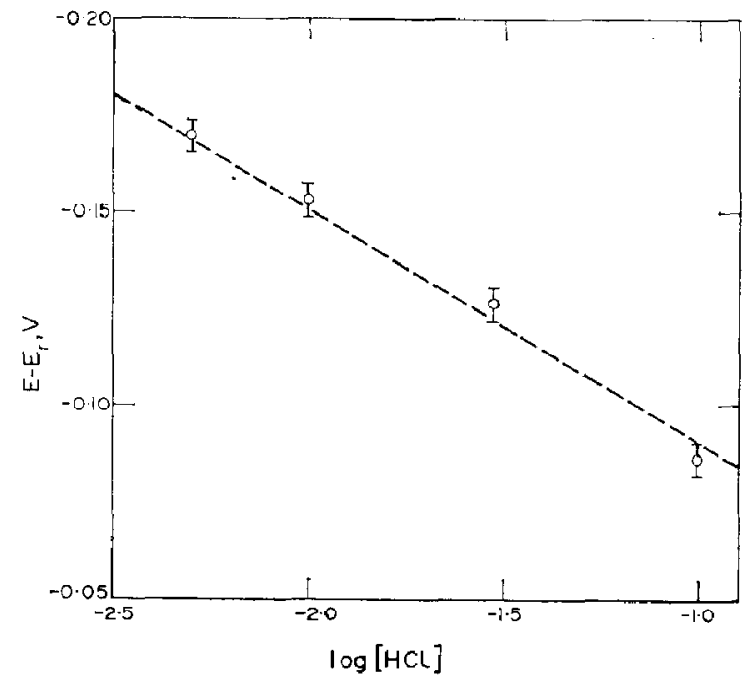

Fig. 7. Dependence of $E-E_{r}$ on $\log$ (hydrogen chloride concentration). Data obtained from Fig. 2 at $3.17 \times 10^{-5}$ $\mathrm{A} / \mathrm{cm}^{2}$, constant chloride ion concentration and $25^{\circ} \mathrm{C}$.

\section{Temperature effect}

The increase of temperature provokes, at a constant potential, a current increase (Fig. 1) which can be plotted in terms of an Arrhenius plot (Fig. 8). The experimental activation energy, $\Delta H^{*}$, decreases as the overvoltage $E-E_{\mathrm{r}}$ becomes more cathodic, according to the expression:

$$
\Delta H_{E-E_{r}}^{ \pm}=\Delta H_{0}^{*}-\frac{F}{2}\left|E-E_{r}\right| \text {. }
$$

In the range $0 \geq E-E_{r} \geq-0.25 \mathrm{~V}, \Delta H_{0}^{*}$ is 18 $\pm 3 \mathrm{kcal} / \mathrm{mole}$. 


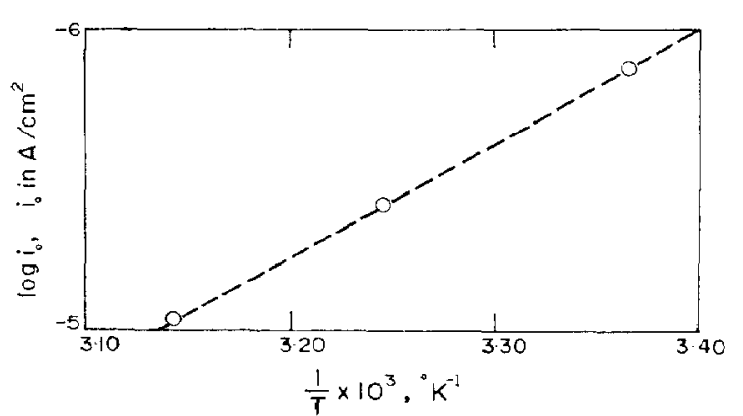

Fig. 8. Arrhenius plot for the apparent current density at $E_{r}$. The experimental activation energy from this plot is $17.5 \mathrm{kcal} /$ mole. Data obtained for a voltammogram run at $10 \mathrm{mV} / \mathrm{s}$ with a rotation speed of $32 \cdot 7 / \mathrm{s}$ and a solution composition $0 \cdot 100 M \mathrm{HCl}+1 M \mathrm{LiClO}_{4}$.

\section{DISCUSSION}

When a nickel electrode is dipped into a $\mathrm{HCl}-$ DMSO solution it attains a rest potential which principally depends on the hydrogen chloride concentration. If the electrode is cathodised then the hydrogen evolution occurs and when it is anodised, then the metal dissolves. On switching the current off, either cathodic or anodic, the rest potential returns rather slowly to its initial value. These metalsolution potentials are related to the corrosion process just described. Their values should be comprised, in principle, between the potentials of the metalmetal ion electrode and the potential of the hydrogen electrode in DMSO, in the absence of any passivation or inhibition effect. The latter potential can be estimated from the activity coefficients for the hydrogen ion transfer from water to DMSO. Kolthoff et al[10] obtained from relative acidity constants a value for $\log { }^{\mathrm{H} 2}{ }^{\circ} \Gamma_{\mathrm{H}^{+}}^{\mathrm{DMO}}=-1 \cdot 5 \pm 0.5$, at $25^{\circ} \mathrm{C}$, which corresponds to a difference between the standard potential of the hydrogen electrode in DMSO and in water, $\left(E_{\mathrm{H}+(\mathrm{DMsO})}^{\mathrm{O}}-E_{\mathrm{H}+\left(\mathrm{H}_{2} \mathrm{O}\right)}^{\mathrm{O}}\right)$, equal to $-0.090 \pm 0.027 \mathrm{~V}[11,12]$.

Courtot-Coupez, Laouénan and Le Démezet[13], after Strehlow's hypothesis that the standard potential of the ferrocene-ferrocinium couple is independent of the solvent[14], obtained a value for $\log { }^{\mathrm{H} 2 \mathrm{O}} \Gamma_{\mathrm{H}^{+}}^{\mathrm{DMSO}}$ equal to $-5 \cdot 8 \pm 0 \cdot 1$, at $25^{\circ} \mathrm{C}$, which corresponds to a difference $\left(E_{\mathrm{H}+\left(\mathrm{OM} \mathrm{MSO}^{\mathrm{O}}\right)}-E_{\mathrm{n}+(\mathrm{H} 2 \mathrm{O})}^{\mathrm{O}}\right)$ equal to $-0.340 \mathrm{~V}$. In any case, the standard hydrogen electrode potential in DMSO is more negative than in water solutions, which is due to the stronger protophilic character of DMSO as compared to $\mathrm{H}_{2} \mathrm{O}$. Therefore, from the above mentioned quantities, in the scale, the normal hydrogen electrode in DMSO should be located either at -0.334 $\pm 0.030 \mathrm{~V}$, or $-0.584 \pm 0.010 \mathrm{~V}$.

Independently of the discrepancies of the theoretical values, the measured rest potentials appear always more positive than any of them, probably indicating a modification of the metal surface caused either by the ions present in the solution or molecules produced as minor impurities during the cathodic reaction.

The Tafel slopes obtained with the solutions of low $\mathrm{HCl}$ concentration, in the presence of supporting electrolyte under stirring, are very close to the ratio $2 R T / F$. Higher Tafel slopes resulted with solutions containing high $\mathrm{HCl}$ concentrations. For the latter the Tafel region covers a relatively shorter $\log$ (current) range, particularly at higher temperatures. Therefore, the results obtained with the more diluted $\mathrm{HCl}$ solutions yield a definite set of parameters which allow a relatively simple mechanistic interpretation of the reaction under quasisteady state conditions. The cathodic Tafel slope, the different reaction orders with respect to hydrogen ion, the dependence of the overvoltage and of the rest potential on the concentration of hydrogen ions, are in agreement with the following reaction pathway:

$$
\begin{aligned}
\mathrm{H}^{+}(\text {solv })+\mathrm{Ni}(e) & =\mathrm{Ni}(\mathrm{H}), \\
(e) \mathrm{Ni}(\mathrm{H})+\mathrm{H}^{+}(\text {solv }) & =\mathrm{Ni}+\mathrm{H}_{2} .
\end{aligned}
$$

This reaction path, involving either step I or step II as rate determining, under Langmuir conditions, yields theoretical kinetic parameters which agree reasonably well with the experimental ones, as shown in Table 2. A mechanism involving a hydrogen adatom recombination step as $r d s$ under either Langmuir or Temkin conditions should, in principle, be discarded. Let us try a further analysis for determining the more likely rate determining step. For this purpose, some relevant facts are obtained from non-stationary measurements. The apparent absence of any appreciable adsorption pseudocapacitance contribution of hydrogen adatoms to the electrochemical double layer, seems to favour reaction I over reaction II as rate determining. If this contribution existed to any extent, it would affect the structure of the double layer and the measured capacitance would appear as potential dependent. If reaction $I$ is rate determining, under steady state both steps would occur at the same rate, so that:

$$
\begin{aligned}
k_{1} a_{\mathbf{H}^{+}}(1-\theta) \exp \left[-\frac{\alpha_{1} \Delta \phi F}{R T}\right] \\
=k_{11} \theta a_{\mathrm{H}^{+}} \exp \left[-\frac{\alpha_{11} \Delta \phi F}{R T}\right],
\end{aligned}
$$

where $k_{1}$ and $k_{11}$ are the specific rate constants. $\Delta \phi$ is the potential difference at the reaction interface; $a_{\mathrm{H}^{+}}$is the activity of hydrogen ions at the interface; $\theta$ is the degree of surface coverage by hydrogen adatoms and $\alpha_{1}$ and $\alpha_{11}$, are the transfer coefficients for each step, assisting thd corresponding reaction in the cathodic direction. As both steps involve a single charge transfer process, it is reasonably to assume $\alpha_{1}=\alpha_{11}=1 / 2$. Under this circumstances $\theta$ becomes potential independent. 
Table 2. Comparison of the theoretical kinetic parameters at $25^{\circ} \mathrm{C},(\alpha=0.5)$, (concentrated solutions and Langmuir conditions) with experimental data

\begin{tabular}{|c|c|c|c|}
\hline \multirow{2}{*}{ Parameter } & \multicolumn{2}{|c|}{ Theoretical } & \multirow{2}{*}{ Experimental } \\
\hline & (I) $r d s$ & (II) $r d s$ & \\
\hline$\left[\frac{\partial\left(E-E_{F}\right)}{\partial \log i}\right]_{C_{H+, \psi_{1}}}$ & $-2 \cdot 3\left(\frac{2 R T}{F}\right), \theta \rightarrow 0$ & $\begin{array}{l}-2 \cdot 3\left(\frac{2 R T}{3 F}\right), \theta \rightarrow 0 \\
-2 \cdot 3\left(\frac{2 R T}{F}\right), \theta \rightarrow 1\end{array}$ & $\begin{array}{l}(-116) \text { to }(-124) \mathrm{mV} \\
(\text { rde }) \\
(-133) \text { to }(-168) \mathrm{mV} \\
\text { (at rest) }\end{array}$ \\
\hline$\left[\frac{\partial\left(E-E_{r}\right)}{\partial \log C_{\mathbf{H}+}}\right]_{i}$ & $2 \cdot 3\left(\frac{R T}{F}\right), \theta \rightarrow 0$ & $\begin{array}{l}2 \cdot 3\left(\frac{3 R T}{4 F}\right), \theta \rightarrow 0 \\
2 \cdot 3\left(\frac{R T}{F}\right), \theta \rightarrow 1\end{array}$ & $60 \pm 10 \mathrm{mV}$ \\
\hline$\left[\frac{\partial \log i}{\partial \log C_{\mathrm{H}^{+}}}\right]_{\psi 1, \phi M}$ & $1, \theta \rightarrow 0$ & $\begin{array}{l}2, \theta \rightarrow 0 \\
1, \theta \rightarrow 1\end{array}$ & $1 \pm 0 \cdot 1$ \\
\hline$\left[\frac{\partial \log i}{\partial \log C_{H+}}\right]_{E-E_{r}}$ & $0.5, \theta \rightarrow 0$ & $\begin{array}{l}0.5, \theta \rightarrow 0 \\
0.5, \theta \rightarrow 1\end{array}$ & $0.46 \pm 0.1$ \\
\hline
\end{tabular}

The experimental cathodic current-potential curves obtained with low $\mathrm{HCl}$ concentration $(0.005-0.03 M)$ can be, however, calculated with the relationship derived by Vetter[15], for the above mentioned consecutive reaction scheme, under $\theta \ll 1$,

$$
\begin{aligned}
i=i_{0, \mathrm{I}} & \exp \left[-\frac{\left(1-\alpha_{1}\right) F}{R T}\left(E-E_{\mathrm{r}}\right)\right] \\
& \frac{1-\exp \left[\frac{2 F}{R T}\left(E-E_{\mathrm{r}}\right)\right]}{1+\frac{i_{0,1}}{i_{0, \mathrm{II}}} \exp \left[\frac{\left(1+\alpha_{1}-\alpha_{11}\right) F}{R T}\left(E-E_{\mathrm{r}}\right)\right]},
\end{aligned}
$$

where $i_{0, \mathrm{r}}$ and $i_{0,11}$ are the current densities at the rest potential, $E_{r}$, corresponding to reaction steps $I$ and II, respectively. Results fit equation (4) after taking $\alpha_{1}=\alpha_{1 I}=0.5$ and $i_{0,1}=10 i_{0,11}$. At high cathodic potentials equation (4) implies a Tafel line with a slope equal to $2 R T / F$, and involves only the kinetic parameters related to the first step.

If reaction $I$ is rate determining, the mechanism is not definitely established, since the following fast reaction could be either step II or a recombination of the hydrogen adatoms. The stoichiometric number which is required for this distinction can not be safely derived from the present results.

The high Tafel slopes observed particularly with the more concentrated $\mathrm{HCl}$ solutions, can also be interpreted in terms of reaction $I$ as $r d s$. The high Tafel slopes are favoured in the non-stirring solutions and when the temperature is increased. To explain these results some facts recently reported are rele- vant. There is a heterogeneous reaction between hydrogen and DMSO yielding, at least on platinum, a bound film of reduction products, probably dimethylsulphide (DMS)[16]. This substance has been detected as an impurity formed during the cathodic discharge of ammonium ion dissolved in DMSO on platinum and it affects the kinetics of the reaction[17]. Furthermore, the inhibiting action of organic sulphides and sulphoxides on the cathodic and anodic reactions occurring on iron in $1 \mathrm{~N} \mathrm{HCl}$ aqueous solutions is known, the sulphide being preferentially adsorbed than the sulphoxide[18,19].

On the basis of these findings it is reasonable to interpret the high Tafel slopes in terms of a variation of the impurity coverage with potential. The effect of the impurity on the Tafel slope for a slow discharge mechanism, at potentials greater than $0.1 \mathrm{~V}$ from the electrocapillary maximum, reflects on the current density as follows[20]:

$$
\begin{aligned}
i=k_{\mathrm{I}} a_{\mathrm{H}}+\frac{\mathrm{C}_{\text {Dмsо }}}{\mathrm{C}_{i} \mathrm{~K}} \exp \left[\frac{\Delta \mu N V^{\prime}}{\delta R T}\right] \\
\quad \exp \left[-\left(\beta+\frac{\Delta \mu N}{\delta F}\right) \frac{F\left(E-E_{\mathrm{r}}\right)}{R T}\right],
\end{aligned}
$$

where $C_{D M s o}$ and $C_{l}$ are the concentration of the solvent and the organic impurity respectively; $K=\exp \left(\Delta F_{\mathrm{DMSO}}-\Delta F_{t}\right) / R T, \Delta F_{\mathrm{DMSO}}$ and $\Delta F_{t}$ are the free energies of adsorption of the solvent and the organic impurity; $\Delta \mu$, is the difference in dipole moments of the impurity and the solvent molecule; $V^{\prime}$ is the potential of the electrode with respect to the electrocapillary maximum, and $\delta$ is the thickness 
of the double layer. According to equation (5), the Tafel slope under these circumstances becomes:

$$
b_{T}=-\frac{2 \cdot 303 R T}{F}\left[\beta+\frac{\Delta \mu N}{\delta F}\right]^{-1} .
$$

In order to calculate the higher limit of the Tafel slope, on the assumption that one solvent molecule and one inhibitor molecule are competing for each adsorption site, we take the following constants[20]: $\mu_{\text {DMSO }}=3.9 \times 10^{-18}$ esu; $\mu_{\mathrm{DMS}}=1.45 \times 10^{-18}$ esu; $\beta=0 \cdot 50 ; N=6.02 \times 10^{23} ; F=3 \times 10^{14}$ esu; $\delta=$ $3 \times 10^{-8} \mathrm{~cm}$. At $25^{\circ} \mathrm{C}, b_{T}$ is equal to $176 \mathrm{mV}$ per decade, a figure which is close to the experimental one. It should be mentioned that the same increase of the cathodic Tafel slope due to the presence of organic sulphides $\left(10^{-4} M\right.$ dibenzylsulphide) has been observed for the hydrogen discharge reaction on iron in $1 \mathrm{~N} \mathrm{HCl}$ aqueous solutions [18].

The same analysis in terms of reaction mechanism solely controlled by step II leads to a decrease of the Tafel slope due to the competitive adsorption between the impurity and hydrogen atoms for electrode sites[17].

Therefore, the higher current densities reached with the more concentrated solutions, the increase of temperature and the nonstirring condition, mean positive contributions for more casily attaining a higher organic impurity concentration (dimethylsulphide) at the reaction interface, with the corresponding increase of the cathodic Tafel slope. These facts appears then as a further support to reaction I as rate determining.

Finally, it should be mentioned that, within the range from -0.1 to $-0.3 \mathrm{~V}$ the experimental activation energy is close to the value reported for acid aqueous solutions on the same metal, at temperatures where tunnel effect contribution is negligible $[1,22,23]$. Its dependence on potential apparently would correspond to the expectations of the mechanisms described, although because of the inhibiting effect just discussed no definite conclusions from the temperature dependence of the reaction rate can be drawn.

Acknowledgement-This work is part of the research program of INIFTA sponsored by CONICET, UNLP and
CIC (Bs. As). A. B. Delgado thanks the CONICET for the fellowship granted during 1970-1972.

\section{REFERENCES}

1. J. A. Olabe and A. J. Arvía, Electrochim. Acta 14, 785 (1969).

2. J. A. Olabe and A. J. Arvía, Electrochim. Acta 15, 1685 (1970).

3. D. Posadas, J. J. Podestá and A. J. Arvía, Electrochim. Acta 15, 1225 (1970).

4. D. Posadas and A. J. Arvía, Electrochim. Acta; 18, 205 (1973).

5. J. Courtot-Coupez and $M$, Le Démezet, $C$. $r$. hebd. Seanc. Acad. Sci. Paris 266, 1438 (1968).

6. D. Posadas, A. J. Arvía and J. J. Podestá, Electrochim. Acta 16, 1025 (1971).

7. D. Posadas, A. J. Arvia and J. J. Podestá, Electrochim. Acta 16, 1041 (1971).

8. V. Levich, Physicochemical Hydrodynamics, Chap. 2, Prentice-Hall, Englewood Cliffs, New Jersey (1962).

9. A. Delgado, A. J. Arvía and D. Posadas; in preparation.

10. I. M. Kolthoff, M. K. Chantooni, Jr. and S. Bhowmik, J. Am. chem. Soc. 90, 23 (1968).

11. C. Richtie and R. Uschold, J. Am. chem. Soc. 87, 1004 (1965).

12. E. M. Arnett, Progr. phys. Org. Chem. 1, 363 (1963).

13. J. Courtot-Coupez, A. Laouénan and M. Le Démezet, C. r. Acad. Sci. hebd. Seanc. Paris 267, 1475 (1968).

14. H. Strehlow, The Chemistry of Non-Aqueous Solvents, Edited by J. J. Lagowski), Chap. 4. Academic Press, New York (1966).

15. K. Vetter, Electrochemical Kinetics, p. 528. Academic Press, New York (1967).

16. T. C. Franklin and H. Kagawa, Electrochim. Acta 17, 1213 (1972).

17. C. Martinez, A. J. Arvía and J. Wargon, Electrochim. Acta; 17, 2153 (1972).

18. G. Trabanelli, G. L. Zucchini, F. Zucchi and V. Carassiti, Br. Corrosion J. 4, 267 (1969).

19. F. Zucchi, G. Trabanelli and G. Gullini, Electrochim. Metal. 3, 407 (1968).

20. S. Srinivasan, Dissertation in Chemistry, p. 183. Univ. Philadelphia, (1963).

21. A. L. McClellan, Tables of Experimental Dipole Moments, W. H. Freeman, San Francisco and London (1963).

22. B. E. Conway, Trans. Symp. Electrode Processes, p. 267. Wiley, New York (1961).

23. M. Salomon and B. E. Conway, Discuss. Faraday Soc. 39, 223 (1965). 